\title{
Not just digital natives: Integrating technologies in professional education contexts
}

Erika E. Smith

Mount Royal University

\author{
Renate Kahlke \\ Royal College of Physicians and Surgeons of Canada
}

\section{Terry Judd}

University of Melbourne

In 2001, Prensky characterised a new generation of learners entering higher education as digital natives - naturally digitally literate and inherently proficient users of technology. While many educational technology researchers have long argued for the need to move beyond the digital native assumptions proposed by Prensky and other futurists, a critical review of the literature reveals that this concept remains influential in academia broadly and within professional education specifically. In light of this, we propose an alternative approach to technology integration in professional education settings that aims to avoid unhelpful digital native stereotypes by instead developing digital literacies in ways that leverage technological affordances. By building digital literacies across the procedural and technical, cognitive, and sociocultural domains connected to professional competencies, learners can effectively adopt and utilise emerging technologies through professional digital practices.

\section{Implications for policy and practice:}

- A research-informed model can help educators to avoid digital native stereotypes by instead focusing on digital literacies that can leverage technological affordances and build requisite competencies.

- Aligning technological affordances with pedagogical strategies can facilitate key knowledge and skills needed for effective and meaningful integration of technologies, particularly in professional education settings.

- By developing digital literacies across three domains, educators and learners can more effectively incorporate emerging technologies required for professional digital practices.

Keywords: social media, professional learning, digital literacies, digital natives, critical review

\section{Introduction}

At the turn of the twenty-first century, Prensky (2001) introduced the concept of learners as digital natives in what is likely the most frequently cited article on learners and technology ever (having over 26,000 citations in Google Scholar as of January 2020). Drawing on the slightly earlier net generation and millennial concepts popularised by Tapscott (1998), Howe and Strauss (2000) and others, Prensky described a generation of learners who had grown-up surrounded by and immersed in technology. These young learners were purported to be digitally skilled and literate, inherently comfortable and proficient with a range of technologies, avid and effective multitaskers, and active producers (not just consumers) of content (Kennedy et al., 2007; Smith, 2012). Moreover, Prensky argued that use of technology was rewiring young learners' brains, requiring a fundamental change to the way they were taught. According to Prensky, digital technology was both the cause of and solution to this change. Complicating matters, Prensky believed that most educators in older generations - so-called digital immigrants - had a limited understanding of how learners viewed and used technology, and were ill-equipped to appreciate let alone support learners whose needs had been transformed and enhanced by technology. While these ideas have drawn considerable criticism (Bennett, Maton, \& Kervin, 2008), leading Prensky to modify his views somewhat over time (Prensky, 2009), they remain popular, including among many educators (De Bruyckere, Kirschner, \& Hulshof, 2016). 
Drawing on a critical review of the literature on digital natives and digital literacies, we aim to move beyond common stereotypes through an alternative model for learning about and with technology. We then illustrate this model within professional education for health contexts, where learning expectations and competencies can be leveraged because they are typically explicitly defined.

\section{Critical review}

We conducted a critical review to analyse and connect a diversity of literatures related to the problem of digital native stereotypes and the development of digital literacies for professional education settings. Critical reviews are based on extensive research and critical evaluation of several diverse literatures (Cook, 2016; Eva, 2008). As Grant and Booth (2009) explain, in presenting, analysing, and synthesising material from diverse sources (particularly those that are significant within a field), a critical review provides new conceptual linkages and "typically manifests in a hypothesis or model" (p. 93). As such, a critical review supports our aim to evaluate and synthesise several literatures in order to shift the discourse away from existing myths of students as digital natives by providing an alternative model that supports a research-informed approach to teaching digital literacies.

Informed by a prior comparative literature review (Smith, 2012) and a recent analysis of general and academic search interest in digital natives (Judd, 2018), we engaged in an iterative review of issues related to the digital native stereotype. Through our review and analysis of diverse, significant, and conceptually connected literatures, we aimed to address problematic assumptions that continue to be reinforced by digital native discourse, in particular the notion that technological knowledge and skills are inherently possessed based on generational characteristics. Our focus throughout this process was on digital literacies (see also Smith, Kahlke, \& Judd, 2018), including the ways in which competency in digital practices, and within professional educational and health professional contexts more specifically, can be learned and applied rather than inherently acquired.

\section{Education in the professions}

We have chosen to situate our work within the context of professional education because its regulated, often competency-based nature provides an overarching structure and consistent practice-based examples within which our proposed approach can clearly be illustrated. While the professions encompass fields as diverse as law, engineering, and education, our expertise, and the focus of this paper, lies within the health professional education (HPE) context. This is not to say that our approach is only intended to be applicable to health professions or professional education settings more generally. Arguably much of higher education today within and beyond the professions involves "preparing students for an uncertain, even unknowable future" (Maxwell, 2012, p. 686) by designing authentic learning tasks, outcomes, and assessment that are relevant to students' lives, many of which could potentially be aligned with the development of digital literacies.

\section{The evolution of digital native discourse}

Prensky's ideas clearly struck a chord with many educators (and the popular media), and have continued to do so (according to Google Scholar, his original article has been cited more than 2,000 times each year between 2012 and 2019). On the face of it, Prensky's picture of digital native learners immersed in technology, and therefore able to switch their attention between devices and contexts with ease, is appealing - even more so now than in 2001, given the rise of social media platforms and mobile devices, both of which appear to be profoundly embedded in the personal, social, and academic lives of our learners. But while this zeitgeist involving technology certainly exists, the popular picture of digital natives is not supported by the research. From about 2006 onwards (a timeline that interestingly coincides with the rapid rise in academic citations of Prensky's article) large-scale studies of learners' use of and preferences for technology started to appear (Kennedy, Judd, Churchward, Gray, \& Krause, 2008; Margaryan, Littlejohn, \& Vojt, 2011; Oliver \& Goerke, 2007), painting a very different picture than Prensky's. While some learners did appear to fit digital native stereotypes, many (if not most) did not. Learners' use of, skills with, and preferences for technology were neither well-developed nor uniform (Bullen, Morgan, \& Qayyum, 2011; Hargittai, 2010; Jones, Ramanau, Cross, \& Healing, 2010). Moreover, while differences clearly existed, the technology-related skills, preferences, and requirements 
of learners and educators weren't necessarily at odds (Waycott, Bennett, Kennedy, Dalgarno, \& Gray, 2010).

By around 2010-11 the evidence appeared to be in - the digital native was a stereotype, and according to leading researchers and practitioners within the educational technology community, not a particularly accurate or useful one (Bennett \& Maton, 2010; Kennedy, Judd, Dalgarno, \& Waycott, 2010; Selwyn, 2009). More recently, emerging studies around brain plasticity suggest there is some merit to Prensky's idea that technology can change the way that people learn (Bavelier, Green, \& Dye, 2010). However, it seems equally clear that not all of these changes are for the good. For example, there is a growing body of research on the negative impacts of multitasking and social media on learning and academic performance (Junco, 2012; Loh \& Kanai, 2016; Moisala et al., 2016). Furthermore, Twenge's (2017) generational analysis details a growing mental health crisis for young people "shaped by the smartphone and by the concomitant rise of social media" (para. 6). At the very least, the effects of increasing integration of technology are much more complex than Prensky's original ideas suggest.

The educational technology community appears to be leading the movement away from Prensky's ideas, with a clear decline in journal articles within that field mentioning digital natives or citing Prensky and like-minded authors' works. Meanwhile, interest in digital natives within the broader academic literature continues to rise (Judd, 2018). This includes the realm of professional education. As an example, in the general context of medical education, an advanced Google Scholar search in January 2020 using the terms digital natives in combination with medicine, learning and education produced over 18,000 results, with more than half of these published during the past 5 years. Of course, not all of these citations are necessarily supportive of Prensky's ideas, but the term's usage suggests that it is widely used to label, if not embody, our learners' relationship with technology. For example, within a recent publication examining social media in health professional education, the authors state:

Teaching professionalism, in general, offers challenges for educators, and these challenges are amplified when the topic moves into cyberspace, where students are digital natives and faculty are generally digital immigrants. (Brisson, Fisher, LaBelle, \& Kozmic, 2015, p.

This quotation and others like it serve to highlight the sorts of problems that can arise, perhaps even unintentionally, when we uncritically adopt the digital native stereotype - encouraging us to believe that, when technology is involved, learners will "just get it", despite considerable evidence to the contrary. When abilities to use simple functions of technology become conflated with possessing higher-level capabilities, such as the development and effective application of critical digital literacy skills, we miss out on teachable moments. By framing learning issues through a technologically deterministic lens, focusing on technologies rather than people's developmental processes, we increase the likelihood of perpetuating digital native stereotypes (e.g., Jones, 2011).

That is not to say, however, that technology doesn't and shouldn't play a key and increasing role in how we teach our learners, how they learn, and how they will eventually apply their knowledge and skills in professional practice. Our learners may not be as digitally literate or inherently skilled as we perceive them to be, but the potential affordances offered by the technologies that they prefer or need to use are real. Technology has enhanced education and brings particular benefits that can be leveraged in professional educational contexts where specified competencies and outcomes are consistently articulated and tracked, and therefore provide a clear, explicit educational framework upon which a new approach to integrating technologies can be bolstered. The challenge is to leverage these affordances in a way that is grounded in sound evidence, theory, and design. Only then can we effectively support learners, educators, and institutions in preparing skilled, agile, and practice-ready graduates.

\section{An alternative approach}

Whereas digital native advocates maintain that younger students already possess the knowledge and abilities needed for understanding and using technologies, the defining elements of digital literacies instead emphasise the importance of learning to effectively use technologies as an ongoing process. Building upon and integrating key facets of the literature on digital literacies that can help to move away from these digital native stereotypes, our alternative approach to learning about and with technologies in 
professional education settings is then framed around two core themes - ways to align technological affordances with pedagogy, and through this, the development of learner competencies. The first offers a focus on what particular technologies can (and cannot) offer for learning and practice. The second examines the broad range of knowledge and skills required for learners in professional contexts to effectively integrate unique technologies in practice.

\section{Digital literacies and competencies}

Understanding how technological knowledge and skills are purposefully developed, rather than somehow innately acquired or inherently possessed by learners of a certain age, can help educators to move beyond digital native stereotypes by scaffolding digital literacies within broader curricula. Our understanding of the term digital literacies has evolved considerably since it was popularised in the late 1990s. Contrast for example Gilster's simple notion of "mastering ideas, not keystrokes" (1997, p. 15), with more recent definitions including "the capabilities which fit an individual for living, learning and working in a digital society" (Jisc, 2015), and "the ability to use information and communication technologies [ICTs] to find, evaluate, create, and communicate information, requiring both cognitive and technical skills" (American Library Association, 2012, para. 2). These more detailed conceptions of digital literacies also clearly relate to information literacies (skills for effectively finding, evaluating, and using information (American Library Association, n.d.), as well as media literacies (Hobbs, 2010), multiliteracies (Baker, 2010), and new literacies (Coiro, Knobel, Lankshear, \& Leu, 2014; Lankshear \& Knobel, 2003), ultimately encompassing all new forms of literacy involving digital technologies.

Because there are varying definitions of digital literacies, many of which relate to and overlap with a number of other contemporary literacies, synthesising the conceptual elements of digital literacies in a way that is concise and well-grounded is useful. Revising and integrating these overarching concepts with key points highlighted by Ng (2012) and Willcockson and Phelps (2010), specifically for application within a professional education context, we suggest that digital literacies should be fostered within three interconnected domains:

1. Procedural and technical: the operational, procedural, or technical skills required to functionally utilise technologies effectively and productively;

2. Sociocultural: the meaningful ways in which technologies are shaped by and reflect sociocultural contexts within which they are developed and employed; and

3. Cognitive: the need to process and relate information regarding cognitive aspects of technology use, for instance, by forming schemas for information retrieval and making metacognitive connections (Smith et al., 2018).

Promoting digital literacies within these three interrelated domains builds upon a strong foundation of educational research and practice that reflects and connects to well-known behavioural, sociocultural, and cognitive learning theories in a digital age.

Extending the tenets of digital literacies, there are several frameworks for building competence with digital technologies, such as Jisc's (2016) Digital Capabilities Framework and the European Commission's DIGCOMP: A Framework for Developing and Understanding Digital Competence in Europe (Ferrari, 2013). Ferrari notes that "digital competence can be broadly defined as the confident, critical and creative use of ICT to achieve goals related to work, employability, learning, leisure, inclusion and/or participation in society" (p. 2). Digital competence is a requisite component of digital agency, the ability to adapt to and feel in control in a digital world (Passey et al., 2018). In professional contexts, particular facets of digital competence - for example, the information, communication, contentcreation, safety, and problem-solving competencies that Ferrari outlines - are manifested in disciplinespecific ways as they are translated into competency-based frameworks for the profession. Within such competency-based settings, it is therefore valuable to explicate why and how digital knowledge and skills should be developed within the context of the profession's competency frameworks, using these disciplinary footholds in education and practice. Our model aims to consider professional education and practice by connecting specific HPE competencies to principles of digital literacies in three integrated domains, rather than within a more generic digital competency framework. 


\section{Technological affordances for professional education}

Affordances are the properties, characteristics, or design aspects that suggest how an object should be used (Kaptelinin, n.d.) and the related possibilities for (inter)action. In other words, an affordance is "the way a technology or software can be used and what it allows the user to do or not to do" (Willcockson \& Phelps, 2010), and can be as simple as the ability to select an option from a list, and as powerful as the ability to conduct a keyword search of the publicly accessible internet. The concept of affordances directs attention toward what is enabled or constrained by specific technologies, as well as the importance of learning and applying a broad array of technological skills and knowledge (digital literacies) contextually. As such, by focusing our attention on technological affordances as they relate to learning, we can move beyond simplistic digital native stereotypes (Oliver, 2011; Selwyn, 2012). Digital affordances for learning can be thought of as supporting four common types of activities:

1. Administrating and organizing learning (e.g., learning management systems, lecture capture, online assessment tools, tracking academic schedules, etc.),

2. Seeking help and information (e.g., accessing and using scholarly and professional information sources; seeking advice or information by following, posting, or commenting on educational or professional social media sites),

3. Creating, sharing, and communicating information (e.g., formal and informal; educational, professional, and personal; online communities of practice); and

4. Simulating environments for deliberate practice of technical, diagnostic, and communication skills (e.g., virtualised practice for honing procedures, client or patient interactions, professional reasoning, etc.).

These activities aren't necessarily independent, and some key technologies clearly straddle all four. For example, in health professional education, patient record systems in clinical settings can be used for administration (record-keeping), help-seeking (clinical decision-making support), information sharing (shared patient notes), or virtual practice (simulated electronic medical record sandboxes for reasoning and electronic charting practice).

In addition to seeing technologies as required learning content, affordances also allow us to attend to the ways in which technologies can be used to facilitate particular aspects of learning. As such, there is a need for educators and learners to understand what is afforded by technologies "in the context of the dynamic educational ecologies in which they work" (Ellaway, Fink, Graves, \& Campbell, 2014, p. 130). Since learning context is important, examining the alignment between particular technological affordances and desired outcomes in specific educational settings is a necessary step to ensure effective integration of technology for learning. Applying our four common categories of technological affordances to professional education contexts can bolster these alignments contextually.

Whether framed as course objectives, program outcomes, or competencies, Willcockson and Phelps (2010) suggest that educators should aim to match the learning goal or problem at hand to the technological affordance(s) offered while also being mindful of learner characteristics, including varied levels of comfort with different types and aspects of technology. They provide examples of several affordances relevant to HPE, including blogs as a match for reflective journaling goals or wikis for collaborative content creation. However, in discussing what digital technologies can afford for HPE, Ellaway and Masters (2008) caution that "while education, not technology, is the prime goal (and for healthcare, better patient outcomes), we are also aware that we cannot always predict outcomes" (p. 455). Acknowledging that this trajectory toward meeting outcomes is at times fluid, matching affordances to outcomes should be an iterative process supplemented by information and evidence from a variety of sources, including educational research, grey literature, and formative and summative learner observations (Hayman \& Smith, 2015). Nevertheless, alignment between learning outcomes and technological affordances acts as a useful foundation for scaffolding essential digital literacies, an activity that can bring learning about and with technology to the fore of the educational experience and avoid blanket assumptions about digital native learners' technology-related skills and preferences.

While technologies are undoubtedly expected (and intended) to be used as both a facilitator of learning and as a required tool of the trade, explicit teaching of requisite digital knowledge and skills is often lacking (e.g., Ellaway, Graves, \& Greene, 2013). Simply put, we need to put our assumptions about 
learners aside and ensure, whether explicitly through direct intervention or implicitly through embedded teaching about and use of technologies within authentic learning tasks, that they are trained in relevant digital literacies $(\mathrm{Ng}, 2012)$. Returning to the themes of affordances and competencies, this suggests a need for educators to refocus on two key questions: (1) what affordances are offered by a given technology that will support learners in developing their professional competencies, and (2) what broad range of knowledge and skills do learners require in order to effectively integrate a technology in their learning and practice?

With the above in mind, we propose a model for learning design in professional education that integrates digital literacy domains with professional competencies and technological affordances (Figure 1). The intersections of these elements describe the development of digital competencies within authentic educational contexts (Professional Competencies + Domains of Digital Literacy), aligning learning outcomes and technological affordances (Professional Competencies + Core Affordances), and relating afforded learning activities to digital literacy domains (Core Affordances + Domains of Digital Literacy). The model's nexus forges a strong foundation for the effective development and implementation of professional digital practices.

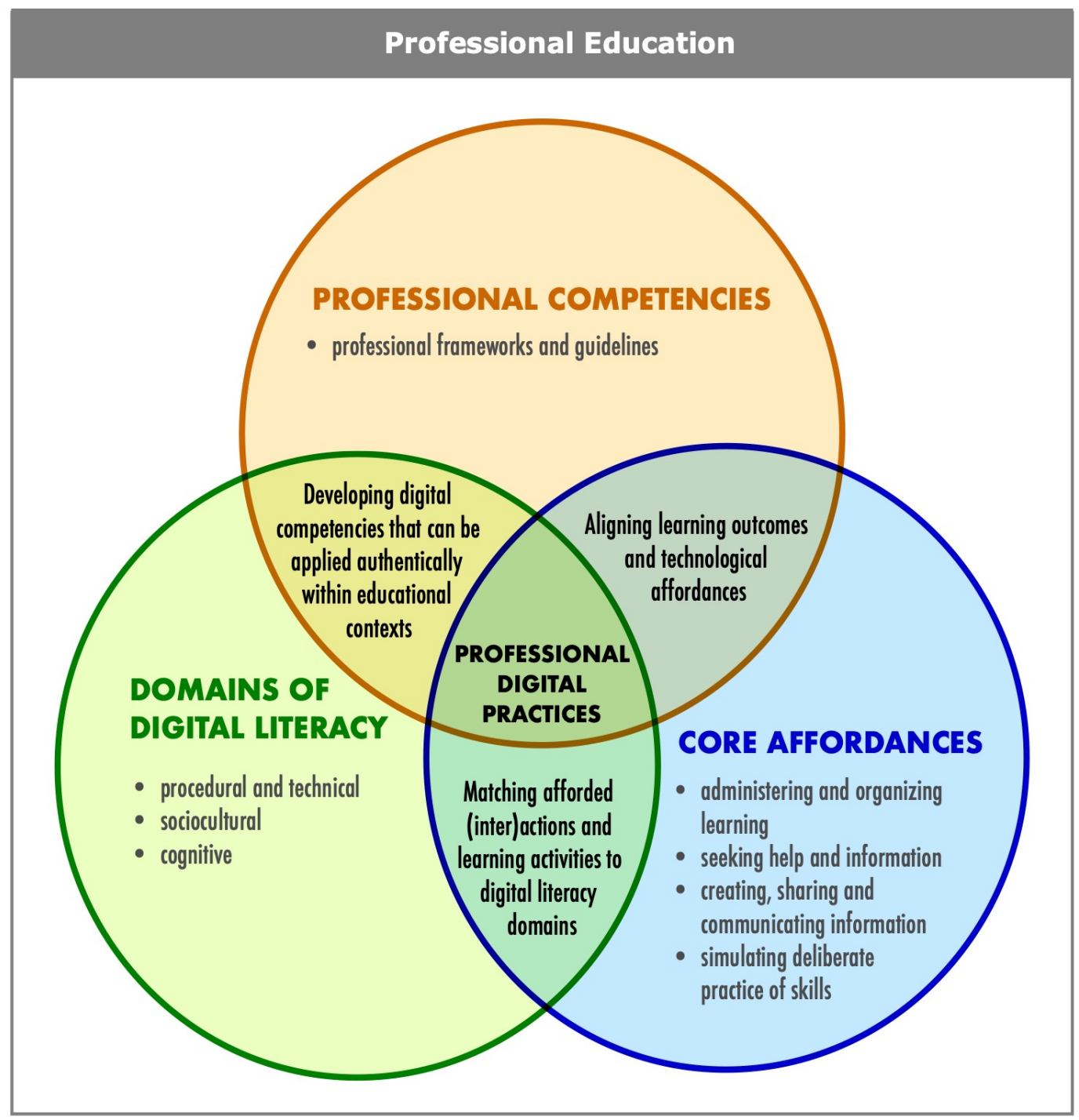

Figure 1. Fostering professional digital practices

This model illustrates three essential elements of professional competencies, affordances, and digital literacy domains that, when aligned and integrated, can build effective digital practices in professional 
education contexts. The model has similarities with the popular TPACK framework for technology integration in teaching (Koehler \& Mishra, 2009; Koehler, Mishra, \& Cain, 2013) and it is worth comparing and contrasting the two. Building on Shulman's (1986) original work, the TPACK framework brings together the three areas of technology, pedagogy, and content knowledge. The most obvious similarity between our model and the TPACK framework is the core nexus created through the three overlapping elements focused on teaching, learning, and technology.

Koehler et al. (2013) view TPACK as being most impactful when the interactions between the three intersecting elements are realised, going beyond an understanding of the individual core components when taken in isolation. This is a stance that we also reinforce within our model. If we consider the overlapping areas of the two models in turn, then the intersection of our Professional Competencies and Core Affordances components map most closely to TPACK's Pedagogical Content Knowledge area, although our focus is on facilitating learning outcomes and affordance alignment in professional contexts rather than strictly the transformation of content within disciplinary teaching. The overlap between our Digital Literacy and Professional Competencies elements is more strongly aligned with TPACK's Technological Content Knowledge, with both being concerned with the ways in which technology and content influence each other, albeit for digital competencies in professional education contexts in our case. Finally, the intersection of our Digital Literacy and Core Affordances components are related to TPACK's Technological Pedagogical Knowledge component, but whereas TPACK focuses more broadly on affordances and "how teaching and learning changes when particular technologies are used in particular ways" (Koehler, 2103, p. 16), ours is on leveraging specific types of (inter)actions for the development and application of the literacies necessary to navigate an increasingly complex digital landscape.

Comparing the two models across their parallel intersecting areas produces a central nexus in each with a clearly different focus - the appropriate and effective use of technology to support professional digital practices in our case and, in the case of TPACK, the much broader aim of utilising technology to best support teaching and learning. Despite these differences, the relationship between the two models remains, and to a large degree is one of scope. Keeping the broader context of TPACK in mind while focusing on the more specific context of our model will have obvious advantages for those who are familiar with TPACK but are keen to apply its general principles in the area of professional education.

\section{Implications for practice}

In the health professions, there have been significant strides toward organising learning through outcomes-based education that is centred around core professional competencies. There are many opportunities within this movement to engage with technology to facilitate learning. Likewise, there are moments where learning about, and through, technology is central to attaining required competencies. As one example of evolving technologies in these contexts, the Royal College of Physicians and Surgeons of Canada's CanMEDS competency framework includes Communicator competencies mandating that learners and trainees "communicate effectively using a written health record, electronic medical record, or other digital technology" (Frank, Snell, \& Sherbino, 2015, p. 17). Similarly, electronic health record competencies are outlined internationally, including by the American Accreditation Council for Graduate Medical Education and the Australian Medical Council, though, in practice, coverage of such health information technologies is often scarce or isolated from, rather than integrated with, other learning contexts or competencies (Elliott, Judd, \& McColl, 2016; Wald, George, Reis, \& Taylor, 2014). While such e-health competencies involve technology as both a facilitator of learning and required learning content, there is evidence that learners need more "deliberate instruction, guidance, and modeling from their preceptors in and around the use of electronic health record" (Ellaway et al., 2013, p. 282). These issues reinforce the consequences of assuming that all learners of a particular age group will have similar understandings of, and abilities with, technology. Instead, educators can focus on what a given technology offers that will support learners to establish their professional competencies, and intentionally develop the knowledge and skills learners require to effectively integrate a technology in their learning and in practice.

One of the key ways that educators can avoid stereotyping learners as digital natives is to deliberately scaffold development of digital literacies by matching the competencies and outcomes that learners are to achieve with the affordances offered by particular technologies. With these affordance-outcome 
relationships in mind, educators can then design learning opportunities that support the development of relevant digital literacies across the procedural and technical, sociocultural, and cognitive domains. To illustrate this learning design process, we consider in detail the example of social media (digital platforms, applications, and websites that allow users to join and develop virtual social networks to communicate and create and share content) in HPE and professional practice.

\section{The case of social media in HPE}

Social media tools and services present unique opportunities and challenges among available technologies used to support learning and practice in that they typically sit outside the control of a particular institution or workplace, making monitoring and enforcing appropriate and effective digital practices particularly difficult. In navigating this tension between benefits and drawbacks, learners describe social media as a double-edged sword that can both help and hinder their learning, depending on the usage context and what is afforded (Smith, 2016a; 2016b). Learners in the health professions also reported using social media for a range of learning-related activities, including: collaborating with peers, reviewing relevant techniques and procedures, keeping up-to-date with current events and real-life health cases, and searching for career and continuing professional development opportunities. While the majority of these activities are learner initiated and informal, there are clear opportunities for social media use in more formal contexts (Fenwick, 2014) and in support of specific competencies, particularly those related to the development of effective communication and collaboration skills in professional settings.

However, there are also a number of challenges to the routine use of social media in HPE. These include their ability to distract, issues related to privacy and anonymity, and questions about the quality and reliability of information shared. Additionally, for health professionals in particular, there can be nuances and challenges involved in maintaining boundaries between their personal and professional identities while preserving an online professional reputation. While health professional learners' use of social media is widespread, there is an unmet and growing demand for training and policies regarding their use (O'Sullivan et al., 2017), feeding into a more general need to proactively build knowledge and skills for digital professionalism within HPE (Ellaway, Coral, Topps, \& Topps, 2015).

Below we provide an example of affordances offered by social media integration in HPE, then explore how developing digital literacies grounded in the three domains can build professional digital practices that are valuable for HPE competencies and contexts.

\section{Meeting professional competencies}

Within HPE, the move toward organising learning around core professional competencies has involved specific mention of learning about or with technology. Several of these competencies relate to a health professional's own use of digital technologies, such as social media, largely in professional but also in personal digital contexts. They also inform how health professionals should assist patients and their family members in accessing and sharing relevant information. For example, in addition to the Communicator competencies noted above, within the CanMEDS competency framework, requirements to demonstrate effective use of emerging technologies, such as social media, are reflected under Professional competencies to "exhibit professional behaviours in the use of technology-enabled communication" (Frank et al., 2015, p. 27). Similarly, the Scholar role specifies "a lifelong commitment to excellence in practice through continuous learning and by teaching others, evaluating evidence, and contributing to scholarship" (p. 24). Whether engaging in scholarly activities of teaching and lifelong learning, demonstrating professional behaviours when using technology, or creating and disseminating knowledge for different health audiences, these competencies involve a range of technologies and increasingly rely upon the use of social media.

To reflect these contemporary professional expectations and competencies, several health professionals and organisations have encouraged the use of social media - for example, using Twitter to facilitate peerto-peer learning or discussions on clinical cases - noting these activities could also be used for assessment of Accreditation Council for Graduate Medical Education (ACGME) milestones (Pearson, Cooney, \& Bond, 2015). As a result, a number of health professional associations have developed (or, are developing) recommendations for social media use that are consistent with professional standards (e.g., Rouprêt et al., 2014). 


\section{Aligning digital literacies with technological affordances}

Drawing on the three domains of digital literacies in our model, educators can help learners to master the procedural and technical, cognitive, and sociocultural aspects of social media to achieve the professional competencies connected to digital practices. For example, from a procedural and technical perspective, educators can support learners to actively develop skills for managing social media profiles and account settings in ways that best reflect professional standards. These technical skills can also help learners in accessing or engaging the best audience for their professional messages or information needs, while at the same time avoiding the sorts of breaches of professionalism and privacy that injudicious (or uninformed) social media use can enable. Rapid and effective development of these skills is critical because inappropriate or unintended online behaviours quickly become a part of our digital footprint, leaving a data trail that can be hard to remove and may have long-lasting personal and professional implications.

From a cognitive perspective, ongoing concerns over supposed digital native strengths, like information literacy skills (Ivanitskaya, O’Boyle, \& Casey, 2006; Judd \& Kennedy, 2011), highlight that learners don't necessarily enter HPE contexts with the knowledge and skills required to effectively integrate social media technologies into their personal and professional lives. Instead, learners require opportunities for deliberate practice that develop these literacies (Farnan et al., 2009; Judd \& Elliott, 2017), including the cognitive knowledge and skills involved in effectively locating, accessing, and assessing information obtained and shared online, particularly through social media platforms. Intentionally embedding metacognitive growth that encourages a lifelong commitment to learning about and through technologies also reflects the key tenet of continuous professional development, a cornerstone of renewal for many professional designations.

Sociocultural implications must also be considered when reflecting on the contextual aspects of the digital literacies involved in engaging with social media. Learners require knowledge and skills to understand the social milieu in which they are working in order to assess how best to share information that achieves their goals, all while maintaining their online professional reputation. These abilities to critically assess often require more nuance than, for instance, simply avoiding posting compromising pictures in public online environments. Rather, learners often have to learn to navigate the rules and norms (both implicit and explicit) of social media in professional settings, which can vary from platform to platform, to communicate messages in ways that are meaningful to their audience, all while maintaining high levels of professionalism. This can be difficult to navigate on social media - with the possible exception of LinkedIn, which aims to help users establish, manage, and promote their professional identities - as many platforms do little to actively promote professionalism, instead relying on the collective integrity of users and automated tools filtering content to ensure that community (or professional) standards aren't breached.

Explicitly building contextualised digital literacies at every stage of HPE, from the undergraduate level through to residency and continuing professional development, can help to address known issues and behaviours related to online professionalism (Garner \& O’Sullivan, 2010; White, Kirwan, Lai, Walton, \& Ross, 2013) and enable learners to make the most of emerging technologies available to them. To foster effective and appropriate professional digital practices, which sit at the nexus of our model, learners would benefit from opportunities to develop digital literacies in all three domains in ways that both support professional competencies and align with related technological affordances.

\section{Opportunities in education and practice}

Within and beyond HPE contexts, there are several opportunities to move beyond digital native stereotypes in ways that have benefits pedagogically and in practice. Based on our critical review, there is clearly a continued need to replace ideas framing all young people as digital natives with evidence-based strategies for teaching and learning with technology within and across contexts and disciplines. Relatedly, rather than relying on tacit assumptions, through our model, we encourage educators and practitioners to make the linkages between pedagogical and technological strategies more explicit; for instance, by articulating affordance-outcome alignment in ways that build competence and promote digital literacies. Furthermore, given the ever-evolving nature of emerging technologies, there is an opportunity to expand continuous professional development for practitioners, as well as a need for enhanced development 
opportunities for educators, all of whom need to be knowledgeable of and competent with digital technologies in their particular settings. The model that we present is one heuristic that we hope can be utilised in the planning and delivery of such development opportunities.

\section{Limitations and future research}

A critical review methodology was suited to the purpose of our research given its strengths for evaluating a diversity of literatures and creating conceptual connections and innovations. However, we also acknowledge the limitations of a critical review. Since the focus is on critically analysing wider conceptual contributions in the research, a critical review, unlike the systematic review and other review methodologies like it, does not provide a mathematical or quantifiably defined assessment of the literature in question (Eva, 2008; Grant \& Booth, 2009).

Our critical review presents key insights from intersecting themes and findings in the literature that offer an alternative approach, moving away from continued stereotypes of all younger learners as digital natives and toward intentional development of digital literacies in professional education settings. Areas for future research include further theoretical and empirical engagement with the model and the conceptual connections presented. In particular, while the model presented here is illustrated in the context of health professional education settings, further empirical and theoretical analysis of the model within other disciplinary and educational contexts would help extend and bolster these findings. Our work also hones in on social media technologies as a contemporary example. Further research on the topics presented here as they apply to other emerging technologies would also be beneficial.

\section{Conclusion}

Despite its popular appeal in the HPE literature and education practice, the digital native stereotype does not accurately reflect the way that younger people - including many learners and practitioners - perceive, use, or interact with or through technology. In educational contexts, failing to question this stereotype has real implications, often leaving learners unsupported and technologies inappropriately aligned with learning needs and contexts. Rather than relying upon unrealistic expectations of learners and technologies, we propose an approach that is informed by affordances (what a technology brings to learning and practice) and digital literacies (the key knowledge and skills required to effectively utilise a technology). Through examples of social media in professional education contexts, we apply key findings from our critical review to illustrate implications for practice via research-based strategies that move from tacit assumptions of learners' digital knowledge and skills to the explicit development of digital literacies across three interconnected domains. Our model seeks to identify and align technology-related procedural and technical, cognitive, and sociocultural digital literacies with core affordances and professional competencies, with the goal of fostering professional digital practices that are necessary within today's health professions contexts. By integrating this research-informed model with contemporary elements of professional practice, educators and practitioners can strive to avoid digital native stereotypes by instead focusing on digital literacies that leverage technological affordances and align with desired competencies.

\section{Acknowledgements}

The authors with to thank Ian Scott, MD \& MSc, Director of the Centre for Health Educator Scholarship and Associate Professor in the Department of Family Practice at the University of British Columbia, and Richard Hayman, MA \& MLIS, Digital Initiatives Librarian and Associate Professor at Mount Royal University, for their reviews of earlier drafts. The first author's research was supported by the Social Sciences and Humanities Research Council of Canada.

\section{References}

American Library Association (n.d.). Information literacy competency standards for higher education. Retrieved from http://www.ala.org/Template.cfm?Section=Home\&template=/ContentManagement/ContentDisplay.cf $\underline{m} \&$ ContentID $=33553$ 
American Library Association (2012). Digital literacy. Retrieved from https://literacy.ala.org/digitalliteracy/

Baker, E. A. (Ed.). (2010). The new literacies: Multiple perspectives on research and practice. New York, NY: Guilford Press.

Bavelier, D., Green, C. S., \& Dye, M. W. (2010). Children, wired: For better and for worse. Neuron, 67(5), 692-701. https://doi.org/10.1016/j.neuron.2010.08.035

Bennett, S., \& Maton, K. (2010). Beyond the 'digital natives' debate: Towards a more nuanced understanding of students' technology experiences. Journal of Computer Assisted Learning, 26(5), 321-331. https://doi.org/10.1111/j.1365-2729.2010.00360.x

Bennett, S., Maton, K., \& Kervin, L. (2008). The 'digital natives' debate: A critical review of the evidence. British Journal of Educational Technology, 39(5), 775-786. https://doi.org/10.1111/j.14678535.2007.00793.x

Brisson, G. E., Fisher, M. J., LaBelle, M. W., \& Kozmic, S. E. (2015). Defining a mismatch: Differences in usage of social networking sites between medical students and the faculty who teach them. Teaching and Learning in Medicine, 27(2), 208-214. https://doi.org/10.1080/10401334.2015.1011648

Bullen, M., Morgan, T., \& Qayyum, A. (2011). Digital learners in higher education: Generation is not the issue. Canadian Journal of Learning and Technology, 37(1), 1-24. https://doi.org/10.21432/T2NC7B

Coiro, J., Knobel, M., Lankshear, C., \& Leu, D. J. (Eds.). (2014). Handbook of research on new literacies. New York, NY: Routledge.

Cook, D. A. (2016). Tips for a great review article: Crossing methodological boundaries. Medical Education, 50(4), 384-387. https://doi.org/10.1111/medu.12983

De Bruyckere, P., Kirschner, P. A., \& Hulshof, C. D. (2016). Technology in education: What teachers should know. American Educator, 40(1), 12-18. Retrieved from https://eric.ed.gov/?id=EJ1094203

Ellaway, R. H., Coral, J., Topps, D., \& Topps, M. (2015). Exploring digital professionalism. Medical Teacher, 37(9), 844-849. https://doi.org/10.3109/0142159X.2015.1044956

Ellaway, R. H., Fink, P., Graves, L., \& Campbell, A. (2014). Left to their own devices: Medical learners' use of mobile technologies. Medical Teacher, 36(2), 130-138. https://doi.org/10.3109/0142159X.2014.917287

Ellaway, R. H., Graves, L., \& Greene, P. S. (2013). Medical education in an electronic health recordmediated world. Medical Teacher, 35(4), 282-286. https://doi.org/10.3109/0142159X.2013.773396

Ellaway, R., \& Masters, K. (2008). AMEE Guide 32: E-Learning in medical education Part 1: Learning, teaching and assessment. Medical Teacher, 30(5), 455-473. https://doi.org/10.1080/01421590802108331

Elliott, K., Judd, T., \& McColl, G. (2016). Utilising mobile electronic health records in clinical education. In S. Bridges, L. K. Chan, \& C. E. Hmelo-Silver (Eds.), Educational technologies in medical and health sciences education (pp. 159-179). https://doi.org/10.1007/978-3-319-08275-2 9

Eva, K. W. (2008). On the limits of systematicity. Medical Education, 42(9), 852-853. https://doi.org/10.1111/j.1365-2923.2008.03140.x

Farnan, J. M., Paro, J. A., Higa, J. T., Reddy, S. T., Humphrey, H. J., \& Arora, V. M. (2009). Commentary: The relationship status of digital media and professionalism: It's complicated. Academic Medicine, 84(11), 1479-1481. https://doi.org/10.1097/ACM.0b013e3181bb17af

Fenwick, T. (2014). Social media and medical professionalism: Rethinking the debate and the way forward. Academic Medicine, 89(10), 1331-1334. https://doi.org/10.1097/ACM.0000000000000436

Ferrari, A. (2013). DIGCOMP: A framework for developing and understanding digital competence in Europe. Retrieved from https:/ec.europa.eu/jrc/en/publication/digcomp-framework-developing-andunderstanding-digital-competence-europe

Frank, J. R., Snell, J., Sherino, J. (Eds.). (2015). CanMEDS 2015 physician competency framework. Ottawa: Royal College of Physicians and Surgeons of Canada. Retrieved from http://www.royalcollege.ca/rcsite/canmeds/canmeds-framework-e

Garner, J., \& O'Sullivan, H. (2010). Facebook and the professional behaviours of undergraduate medical students. The Clinical Teacher, 7(2), 112-115. https://doi.org/10.1111/j.1743-498X.2010.00356.x

Gilster, P. (1997). Digital literacy. New York, NY: Wiley.

Grant, M. J., \& Booth, A. (2009). A typology of reviews: An analysis of 14 review types and associated methodologies. Health Information \& Libraries Journal, 26(2), 91-108. https://doi.org/10.1111/j.1471-1842.2009.00848.x

Hargittai, E. (2010). Digital na(t)ives? Variation in internet skills and uses among members of the "net generation". Sociological Inquiry, 80(1), 92-113. https://doi.org/10.1111/j.1475-682X.2009.00317.x 
Hayman, R., \& Smith, E. E. (2015). Sustainable decision making for emerging educational technologies in libraries. Reference Services Review, 43(1), 7-18. https://doi.org/10.1108/RSR-08-2014-0037

Hobbs, R. (2010). Digital and media literacy: A plan of action. A white paper on the digital and media literacy recommendations of the Knight Commission on the information needs of communities in a democracy. Retrieved from https://eric.ed.gov/?id=ED523244

Howe, N., \& Strauss, W. (2000). Millennials rising: The next great generation. New York, NY: Vintage.

Ivanitskaya, L., O'Boyle, I., \& Casey, A. M. (2006). Health information literacy and competencies of information age students: Results from the interactive online research readiness self-assessment (RRSA). Journal of Medical Internet Research, 8(2), e6. https://doi.org/10.2196/jmir.8.2.e6

JISC (2015). Developing students' digital literacies. Retrieved from https://www.jisc.ac.uk/guides/developing-students-digital-literacy

JISC (2016). Building digital capability. Retrieved from https://www.jisc.ac.uk/rd/projects/buildingdigital-capability

Jones, C. (2011). Students, the net generation, and digital natives. In M. Thomas (Ed), Deconstructing digital natives: Young people, technology, and the new literacies (pp. 30-45). New York, NY: Taylor \& Francis.

Jones, C., Ramanau, R., Cross, S., \& Healing, G. (2010). Net generation or digital natives: Is there a distinct new generation entering university? Computers \& Education, 54(3), 722-732. https://doi.org/10.1016/j.compedu.2009.09.022

Judd, T. (2018). The rise and fall (?) of the digital natives. Australasian Journal of Educational Technology, 34(5), 99-119. https://doi.org/10.14742/ajet.3821

Judd, T., \& Elliott, K. (2017). Selection and use of online learning resources by first-year medical students: Cross-sectional study. JMIR Medical Education, 3(2), e17. https://doi.org/10.2196/mededu.7382

Judd, T., \& Kennedy, G. (2011). Expediency-based practice? Medical students' reliance on Google and Wikipedia for biomedical inquiries. British Journal of Educational Technology, 42(2), 351-360. https://doi.org/10.1111/j.1467-8535.2009.01019.x

Junco, R. (2012). Too much face and not enough books: The relationship between multiple indices of Facebook use and academic performance. Computers in Human Behavior, 28(1), 187-198. https://doi.org/10.1016/j.chb.2011.08.026

Kaptelinin, V. (n.d.). Affordances. In The encyclopedia of human computer interaction (2nd ed.). Retrieved from https://www.interaction-design.org/literature/book/the-encyclopedia-of-humancomputer-interaction-2nd-ed

Kennedy, G., Dalgarno, B., Gray, K., Judd, T., Waycott, J., Bennett, S. J., ... \& Churchwood, A. (2007). The net generation are not big users of Web 2.0 technologies: Preliminary findings. Proceedings Ascilite Singapore, 517-525. Retrieved from http://www.ascilite.org/conferences/singapore07/procs/kennedy.pdf

Kennedy, G., Judd, T., Churchward, A., Gray, K., \& Krause, K. L. (2008). First year students' experiences with technology: Are they really digital natives? Australasian Journal of Educational Technology, 24(1), 108-122. https://doi.org/10.14742/ajet.1233

Kennedy, G., Judd, T., Dalgarno, B., \& Waycott, J. (2010). Beyond natives and immigrants: Exploring types of net generation students. Journal of Computer Assisted Learning, 26(5), 332-343. https://doi.org/10.1111/j.1365-2729.2010.00371.x

Koehler, M., \& Mishra, P. (2009). What is technological pedagogical content knowledge (TPACK)? Contemporary Issues in Technology and Teacher Education, 9(1), 60-70. Retrieved from https://www.learntechlib.org/p/29544/

Koehler, M. J., Mishra, P., \& Cain, W. (2013). What is technological pedagogical content knowledge (TPACK)? Journal of Education, 193(3), 13-19. Retrieved from https://www.jstor.org/stable/24636917

Lankshear, C., \& Knobel, M. (2003). New literacies: Changing knowledge and classroom learning. Buckingham: Open University Press.

Loh, K. K., \& Kanai, R. (2016). How has the internet reshaped human cognition? The Neuroscientist, 22(5), 506-520. https://doi.org/10.1177/1073858415595005

Margaryan, A., Littlejohn, A., \& Vojt, G. (2011). Are digital natives a myth or reality? University students' use of digital technologies. Computers \& Education, 56(2), 429-440.

https://doi.org/10.1016/j.compedu.2010.09.004 
Maxwell, T. W. (2012). Assessment in higher education in the professions: Action research as an authentic assessment task. Teaching in Higher Education, 17(6), 686-696. https://doi.org/10.1080/13562517.2012.725220

Moisala, M., Salmela, V., Hietajärvi, L., Salo, E., Carlson, S., Salonen, O., ... \& Alho, K. (2016). Media multitasking is associated with distractibility and increased prefrontal activity in adolescents and young adults. NeuroImage, 134, 113-121. https://doi.org/10.1016/j.neuroimage.2016.04.011

$\mathrm{Ng}$, W. (2012). Can we teach digital natives digital literacy?. Computers \& Education, 59(3), 1065-1078. https://doi.org/10.1016/j.compedu.2012.04.016

Oliver, B., \& Goerke, V. (2007). Australian undergraduates' use and ownership of emerging technologies: Implications and opportunities for creating engaging learning experiences for the Net Generation. Australasian Journal of Educational Technology, 23(2), 171-186. https://doi.org/10.14742/ajet.1263

Oliver, M. (2011). Technological determinism in educational technology research: Some alternative ways of thinking about the relationship between learning and technology. Journal of Computer Assisted Learning, 27(5), 373-384. https://doi.org/10.1111/j.1365-2729.2011.00406.x

O'Sullivan, E., Cutts, E., Kavikondala, S., Salcedo, A., D'Souza, K., Hernandez-Torre, M., ... \& Last, J. (2017). Social media in health science education: An international survey. JMIR Medical Education, 3(1), e1. https://doi.org/10.2196/mededu.6304

Passey, D., Shonfeld, M., Appleby, L., Judge, M., Saito, T., \& Smits, A. (2018). Digital agency: Empowering equity in and through education. Technology, Knowledge and Learning, 23(3), 425-439. https://doi.org/10.1007/s10758-018-9384-X

Pearson, D., Cooney, R., \& Bond, M. C. (2015). Recommendations from the Council of Residency Directors (CORD) social media committee on the role of social media in residency education and strategies on implementation. Western Journal of Emergency Medicine, 16(4), 510-515. https://doi.org/10.5811/westjem.2015.5.25478

Prensky, M. (2001). Digital natives, digital immigrants part 1. On the Horizon, 9(5), 1-6. https://doi.org/10.1108/10748120110424816

Prensky, M. (2009). H. sapiens digital: From digital immigrants and digital natives to digital wisdom. Innovate, 5(3), 1-9.

Rouprêt, M., Morgan, T. M., Bostrom, P. J., Cooperberg, M. R., Kutikov, A., Linton, K. D., ... \& Winterbottom, A. (2014). European Association of Urology (@, Uroweb) recommendations on the appropriate use of social media. European Urology, 66(4), 628-632. https://doi.org/10.1016/j.eururo.2014.06.046

Selwyn, N. (2009). The digital native-myth and reality. Aslib Proceedings 61(4), pp. 364-379. https://doi.org/10.1108/00012530910973776

Selwyn, N. (2012). Making sense of young people, education and digital technology: The role of sociological theory. Oxford Review of Education, 38(1), 81-96. https://doi.org/10.1080/03054985.2011.577949

Shulman, L. S. (1986). Those who understand: Knowledge growth in teaching. Educational Researcher, 15(2), 4-14.

Smith, E. E. (2012). The digital native debate in higher education: A comparative analysis of recent literature. Canadian Journal of Learning and Technology, 38(3), 1-18. https://doi.org/10.21432/T2F302

Smith, E. E.(2016a). Exploring undergraduate perceptions of meaning making and social media in their learning (Doctoral thesis, University of Alberta, Edmonton, Canada). https://doi.org/10.7939/R33J39B71

Smith, E. E. (2016b). "A real double-edged sword": Undergraduate perceptions of social media in their learning." Computers \& Education, vol. 103, 44-58. http://dx.doi.org/10.1016/j.compedu.2016.09.009

Smith, E. E., Kahlke, R., \& Judd, T. (2018). From digital natives to digital literacy: Anchoring digital practices through learning design. In M. Campbell, J. Willems, C. Adachi, D. Blake, I. Doherty, S. Krishnan, S. Macfarlane, L. Ngo, M. O’Donnell, S. Palmer, L. Riddell, I. Story, H. Suri \& J. Tai (Eds.), Open Oceans: Learning without borders. Proceedings ASCILITE 2018 Geelong (pp. 510-515). Retrieved from https://2018conference.ascilite.org/conference-proceedings/

Tapscott, D. (1998). Growing up digital. New York, NY: McGraw-Hill Companies.

Twenge, J. M. (2017). Have smartphones destroyed a generation? The Atlantic. Retrieved from https://www.theatlantic.com/

Wald, H. S., George, P., Reis, S. P., \& Taylor, J. S. (2014). Electronic health record training in undergraduate medical education: Bridging theory to practice with curricula for empowering patient- 
and relationship-centered care in the computerized setting. Academic Medicine, 89(3), 380-386. https://doi.org/10.1097/ACM.0000000000000131

Waycott, J., Bennett, S., Kennedy, G., Dalgarno, B., \& Gray, K. (2010). Digital divides? Student and staff perceptions of information and communication technologies. Computers \& Education, 54(4), 1202 1211. https://doi.org/10.1016/j.compedu.2009.11.006

White, J., Kirwan, P., Lai, K., Walton, J., \& Ross, S. (2013). 'Have you seen what is on Facebook?' The use of social networking software by healthcare professions students. BMJ Open, 3(7), e003013. https://doi.org/10.1136/bmjopen-2013-003013

Willcockson, I. U., \& Phelps, C. L. (2010). Keeping learning central: A model for implementing emerging technologies. Medical Education Online, 15(1), 4275.

https://doi.org/10.3402/meo.v15i0.4275

Corresponding author: Erika E. Smith, eesmith@mtroyal.ca

Copyright: Articles published in the Australasian Journal of Educational Technology (AJET) are available under Creative Commons Attribution Non-Commercial No Derivatives Licence (CC BY-NCND 4.0). Authors retain copyright in their work and grant AJET right of first publication under CC BYNC-ND 4.0.

Please cite as: Smith, E. E., Kahlke, R., \& Judd, R. (2020). Not just digital natives: Integrating technologies in professional education contexts. Australasian Journal of Educational Technology, 36(3), 1-14. https://doi.org/10.14742/ajet.5689 